\title{
Impact of a non-attentively perceived odour on subsequent food choices
}

\author{
M. Gaillet-Torrent ${ }^{a, b, c}$, C. Sulmont-Rossé ${ }^{a, b, c}, S$. Issanchou ${ }^{a, b, c}, C$. Chabanet ${ }^{a, b, c}, S$.
} Chambaron $* a, b, c$

${ }^{a}$ CNRS, UMR6265 Centre des Sciences du Goût et de l'Alimentation, F-21000 Dijon, France;

${ }^{b}$ INRA, UMR1324 Centre des Sciences du Goût et de l'Alimentation, F-21000 Dijon, France;

${ }^{c}$ Université de Bourgogne, UMR Centre des Sciences du Goût et de l'Alimentation, F-21000 Dijon, France.

marie.gaillet@dijon.inra.fr, claire.sulmont@dijon.inra.fr,_sylvie.issanchou@dijon.inra.fr, claire.chabanet@dijon.inra.fr, schambaron@dijon.inra.fr

* Corresponding author. Tel.: +33 380693532 .

E-mail address: schambaron@dijon.inra.fr

Postal address: S. Chambaron, UMR CSGA - INRA, 17 rue Sully, 21000 Dijon, France

\begin{abstract}
Current research in psychology suggests that unconscious processes influence a significant proportion of choices and decisions. To study the impact of a non-attentively perceived odour on food choices, we used a priming paradigm. We had previously shown that non-attentively perceived fruity odours could impact food choice intentions (on a menu card), guiding participants toward items containing more fruit and/or vegetables. The present study was designed to extend these findings, in a real-life consumption setting. One hundred and fifteen participants took part in this study, and were assigned randomly to either a control or a scented condition. On arrival in the laboratory, they were seated in a waiting room. For the scented condition, they were unobtrusively exposed to a pear odour, while under the control condition the waiting room was non-odorised. Following this waiting period, all participants moved into a non-odorised test room where they were asked to choose, from dishes served buffet-style, the starter, main course and dessert that they would actually eat for lunch. The results showed that participants subjected to the scented condition chose to consume the 'fruity' dessert (compote) more frequently than those who had waited under the control condition, who chose more frequently the dessert without fruit (brownie). In line with the findings of our previous study, these results confirm the idea of priming effects 'specific to the food cue'. To conclude, a non-attentively perceived fruity odour was shown to influence actual food choices, guiding individuals towards more fruity desserts. The involvement of implicit processes in food choices should be taken into account in guidelines and strategies designed to promote healthy eating.
\end{abstract}

Keywords: Priming; Food choice; Odor; Food cue. 


\section{Introduction}

Although it was initially thought that individuals were entirely conscious of the motivations driving their behaviours and choices, current research in psychology and economics suggests that people are not as rational as they imagine (De Martino, Kumaran, Seymour \& Dolan, 2006; Friese, Hofmann \& Wanke, 2008; Friese, Waenke \& Plessner, 2006; Kahneman \& Tversky, 2000). Moreover, a large number of studies in psychology have demonstrated the influence of non-conscious processes on human feelings, behaviour and decision-making (Bargh \& Chartrand, 1999; Bargh \& Ferguson, 2000; Dijksterhuis, Bos, Nordgren \& van Baaren, 2006; Greenwald \& Banaji, 1995). Eating behaviour does not escape from this rule. In fact, this idea was echoed in three recent publications. In the first, published in 2007, Wansink and Sobal estimated that people make a large number of food-related decisions every day. It is easy to imagine that weighing up the pros and cons of all these decisions might be almost impossible. The authors thus pointed out that: "First, we are aware of only a fraction of the food decisions we make. Second, we are either unaware of how our environment influences these decisions or we are unwilling to acknowledge it." (Wansink \& Sobal, 2007, pp. 106). A year later, Finlayson and collaborators stressed the fact that "it cannot be claimed that processes that control the expression of eating habits are necessarily explicit" (Finlayson, King \& Blundell, 2008, pp. 120). These biopsychologists emphasised the point that obviously, a person cannot be aware of the biological changes that operate to control eating behaviours (changes in neuropeptides, hormones or other physiological processes). Even so, from a psychological point of view, the authors assumed that both explicit and implicit processes are involved. Finally, Köster resumed and expanded this last idea in a comprehensive review published in 2009. According to him, "findings about intuitive reasoning and the clear demonstration of the unconscious nature of most of our decision making do not seem to have touched sensory and consumer research, although they probably play a more important role in food-related behaviour than anywhere else" (Köster, 2009, pp. 70).

Therefore, understanding the impact of non-attentively perceived food cues involved in eating behaviour appears to require the contribution of psychology and cognitive sciences, domains in which several paradigms have been developed in order to explore non-conscious influences. One of these paradigms is called 'priming'. In the priming paradigm, subjects are exposed incidentally to a stimulus called a 'prime', which may belong to any sensory modality (visual, auditory, olfactory, etc.). During this exposure, mental representations 
related to the prime are activated. The principle is then to use indirect tests, in order to evaluate the non-conscious effects of activating these mental representations. To date, very few studies have used the priming paradigm to investigate the role of olfactory cues in the food domain (Coelho, Polivy, Herman \& Pliner, 2009; Fedoroff, Polivy \& Herman, 2003). However, the olfactory modality is evolutionarily and functionally closely linked to food (Hoover, 2010). Several studies have demonstrated the effects of odours on physiological (e.g. salivation) or psychological (e.g. disinhibited eating) parameters related to eating behaviours (Jansen \& van den Hout, 1991; Klajner, Herman, Polivy \& Chhabra, 1981; Legoff \& Spigelman, 1987; Rogers \& Hill, 1989). Moreover, although the olfactory modality has long been considered as a 'secondary' sense in humans, food odours seem to form a category of particular importance: we are indeed more efficient to identify food odours than non-food odours (Boesveldt, Frasnelli, Gordon \& Lundstrom, 2010; Fusari \& Ballesteros, 2008). Olfaction presents number of unique features compared to other sensory modalities. It is the only sensory modality that plays a significant role both: (1) as a distal cue, when perceived orthonasaly (ambient odour or odour released by a food before consumption); (2) as a proximal cue, when perceived retronasaly (aroma of a consumed food). Moreover, olfaction is closely linked to emotions (Bensafi et al., 2002a, 2002b; Royet et al., 2000; Zald \& Pardo, 1997; Zald, Lee, Fluegel \& Pardo 1998) that play an important role in eating behaviours (Jacquier, Bonthoux, Baciu, \& Ruffieux, 2012).

In our first study (Gaillet, Sulmont-Rossé, Issanchou, Chabanet \& Chambaron, 2013), we investigated the effect of an olfactory food cue on choice intentions. The participants were seated in a waiting room of the laboratory, which was odorised with a melon odour or a pear odour, or was non-odorised in the control condition. All the participants then moved to a nonodorised test room where they performed a lexical decision task. During this task, they had to decide as quickly and as accurately as possible whether a letter string shown on a computer screen corresponded to an existing word or to a 'non-word' (i.e. a letter string with no meaning). The task comprised non-words, non-food related words, high-energy food words and fruit or vegetable-related words. The participants were then given a menu and asked to select one item from ten for each course in a typical French meal (starter, main course and dessert). Among the ten choices per course category, five items corresponded to foods containing fruit and/or vegetables and five items without fruit or vegetable. The results showed that participants exposed to the melon odour displayed shorter reaction times in the lexical decision task for the word 'melon' only, and tended to choose more starters containing 
vegetables than participants subjected to the control condition. Moreover, participants exposed to the pear odour chose significantly more desserts containing fruit than control participants. This first study led to two main conclusions: (1) a non-attentively perceived fruity odour could activate mental representations closely related to the prime, and have an impact on food choice intentions (on a menu card), guiding participants towards more 'fruit and vegetable'-related items; (2) the incidental exposure to the odour of melon or pear could activate a concept of 'fruit and vegetables' together with the more specific concept of the context of consumption (starter for the melon, which is a fruit mainly consumed as a starter in France, and dessert for the pear). These results highlighted the non-conscious influence that olfactory cues can have on thinking and 'intending' and illustrated the existence of an indirect link between perception and 'intention'. The next step was therefore to demonstrate the influence that an incidental olfactory cue could have on action and not just on intention, namely in a real-life consumption setting (i.e. during a lunch). Based on the results of our first study (Gaillet et al., 2013), we hypothesised that the incidental exposure to the pear odour would impact choices for the desserts, guiding participants toward more 'fruity' desserts, but would not impact choices for the other dishes (starter, main course).

\section{Material and methods}

\subsection{Participants}

One hundred and fifteen participants took part in the priming experiment, and were assigned randomly to either a control (18-50 years old; mean age = 25 years; 16 males and 42 females) or scented condition (18-52 years old; mean age $=27$ years; 15 males and 42 females). To participate in the study, candidates had to fulfil a recruitment questionnaire. Candidates who declared having food allergies or being on a diet were excluded, just as those who had already taken part in a memory or priming study. Moreover, candidates who explicitly reported having some trouble in odour perception (anosmia) or vision (blindness, cataract) were also excluded. In order to ensure that the participants were unaware of the real purpose of the experiment (i.e. the study of olfactory priming), they were told that the experiment was designed to study communication skills and how people interact in the environment where they eat (i.e. false pretence). They were invited for a one-hour session during lunch-time (i.e. from 12:15 to 13:15). They were asked not to wear perfume, and not to smoke during the hour preceding the session. The experimental protocol was approved by the Comite de la Protection des Personnes Est I (Research Ethics Committee) for Dijon. In accordance with 
the procedures of this regulatory body, the participants received written and oral information about the study before signing a consent form. In return for their participation, they received a $€ 10$ voucher.

The choice of the olfactory prime and the characteristics of the dishes proposed for the Menu task were investigated in separate studies that are detailed in the following two sections. The participants of these preliminary experiments were different from those involved in the priming experiment, but shared similar characteristics.

\subsection{Olfactory priming}

The pear food aroma sold by Meilleur du Chef $\odot$ was selected on the basis of our first priming study (Gaillet et al., 2013), in which participants exposed to this odour chose significantly more 'fruity' desserts on a menu card. In a separate experiment, 23 individuals were asked to score pleasantness and fruit typicality of this pear odour on $10 \mathrm{~cm}$ scales. They were also asked to identify this odour by means of a 4-alternative forced-choice identification task. According to the results, this pear odour was rated as and pleasant $(M=7.8 ; S E=0.43)$ and being typical of the fruit category $(M=7.1 ; S E=0.63) .76 \%$ of the participants of this preliminary experiment correctly identified the odour of pear.

The pear odour was encapsulated and diffused in the waiting room of the laboratory using a scent diffuser (Scentys4 \#PSIA-J-000018 v.1.00, Scentys Fragrance(C). An odorisation procedure was designed in order to: (1) obtain a homogeneous distribution of the odorant in the waiting room; (2) obtain an intensity of the odour relatively stable during the priming phase (15 minutes); (3) obtain a very low odour intensity in the room so that participants would not explicitly notice the odour. The procedure adopted consisted in distributing in the room three 30-s puffs, 30 minutes before the beginning of the session. Then, the room remains tightly closed until the participants entered all together into the room. To ensure that this procedure allows having a barely perceptible odour intensity, ten members of the laboratory staff who had not been informed of the presence of the odour were asked to enter into the waiting room after an odorisation trial (these members of the laboratory staff were not subsequently involved in the main experiment). These individuals were asked to report what they thought about the waiting room or whether they noticed anything unusual. None of them had noticed the presence of the odour but they were still able to detect it when the experimenters focused their attention on it. 


\subsection{Menu task}

This task consisted in presenting each participant with dishes served buffet-style and in asking him/her to choose a starter, a main course and a dessert that he/she wanted to eat for lunch (these courses corresponded to a typical French meal). Two choices were proposed for each course: a dish containing fruit or vegetables and a dish without fruit or vegetable (Table 1). None of the dishes offered contained pears. In fact, the dishes were chosen to highlight an indirect link between the exposure to the pear odour and the food choices.

In a separate experiment, 23 individuals were asked to rate each dish using a $10-\mathrm{cm}$ scale anchored with the statements "I do not expect to like it at all"/“I expect to like it very much". Means of ratings on expected liking for each dish are reported in the table 1. It can be noted that all the dishes were globally liked, with means ranged from 6.59 to 7.69 on 10 . In each course category (starter, main course and dessert), expected liking scores were then submitted to an ANOVA with the dish category (fruit and vegetables; without fruit or vegetable) and subject as factors. No significant differences were highlighted between the dishes containing fruit or vegetables and the dishes without fruit or vegetable (starter: $F_{(1,22)}=0.00 ; p=.98$; main course: $F_{(1,22)}=0.01 ; p=.91$; dessert: $\left.F_{(1,22)}=0.03 ; p=.86\right)$.

[Insert table 1 about here]

\subsection{Procedure}

The experimenters waited that all participants were arrived before inviting them all together to enter into the waiting room. The participants remained in the waiting room for precisely 15 minutes, during which they performed a 'lure' task, consisting of completing a questionnaire on communication skills and representational systems (visual, auditory and kinaesthetic). The data collected in this questionnaire were not analysed. The waiting room was non-odorised for the control condition and pear-odorised for the scented condition. An experimenter checked that the 15 minutes spent in the waiting room were quiet, and that the participants did not talk to each other.

Participants were then entered into a non-odorised test room. Folding screens were arranged so that participants entering the room could not see the dishes served buffet-style. An experimenter asked the participants to pass one by one behind the folding screens, where the dishes were displayed. Behind these folding screens, each participant was asked to choose a starter, main course and dessert that he/she wanted to eat for lunch (Menu task). The participants made thus their choice individually, hidden from both the experimenters and the 
other participants. Once all the participants had made their choice, they were offered the dishes they had chosen for their lunch. After their meal, the participants were asked to complete an 'Investigation' Questionnaire, which was designed to ascertain that the participants had not suspected the real goal of the study, and to check that they had not noticed or identified the prime in the waiting room.

A double-blind procedure was used. Firstly, the participants came to the laboratory under a cover story, so they were not informed about the real purpose of the experiment or, of course, regarding the presence of an odour in the waiting room. Secondly, the experimenters who administered the Menu task and 'Investigation' Questionnaire in the test room had not been informed about the condition in which the participants had spent the past 15 minutes in the waiting room (control or scented).

\section{5. 'Investigation' Questionnaire}

The participants were asked to write down in a few words what they believed to have been the goal of the study in which they had just taken part. They were also asked to indicate whether something had surprised them during the study, and if so, if they thought that it might have influenced their behaviour.

\subsection{Data analyses}

The proportion of 'fruit and vegetable' choices was determined for each group and for each course category (starter, main course and dessert). Statistical analyses were performed using the SAS/STAT® statistical software package version 9.3 (SAS Institute Inc., Cary, USA). To compare the proportions of 'fruit and vegetable' choices versus choices of dishes 'without fruit or vegetables', a logit model (generalised linear model with a binomial distribution and logit link) was applied to each course category, with condition (control; scent) as a factor, and unilateral tests. The generalised linear SAS model procedure (PROC GENMOD) was used. All the results reported here were significant at a level of 0.05 . Means $(M)$ are given with associated standard error (SE).

\section{Results}

Looking at the data of the 'Investigation' Questionnaire, it became clear that the participants had no suspicion at all concerning the true goal of the study (i.e. to study the effect of olfactory priming on food choices), and that none of them had noticed the odour in the 
waiting room. Consequently, no participant was excluded after the data collection of the experiment.

The results of the Menu task did not reveal any significant effect of condition on the starter (deviance $=0.71 ; d f=1 ; p=.20$ ) or the main course (deviance $=1.97 ; d f=1 ; p=.32$ ). However, the analyses revealed that participants primed with a pear odour chose to consume the 'fruity' dessert (apple compote) more frequently than participants subjected to the control condition $($ deviance $=11.10 ; d f=1 ; p<.001)$, who more often selected the dessert without fruit or vegetable (brownie) (Fig. 1).

[Insert figure 1 about here]

As mentioned in section 2.3., the 23 participants of the separate experiment who were explicitly asked how they liked the different dishes proposed buffet-style, did not give higher hedonic ratings to the brownie $(M=7.7 ; S E=0.43)$ than to the compote $(M=7.6 ; S E=0.45)$. However, under the control condition, nearly $75 \%$ of the participants chose the brownie over the compote. Interestingly, these results reveal a discrepancy between explicit attitudes and real choices. Consequently, the results concerning the participants subjected to the scented condition were even more striking. The fact that participants in the control condition chose mainly the brownie is in line with the results obtained in our previous study (Gaillet et al., 2013). In this previous study, participants in the control condition intended to choose mainly desserts without fruit rather than fruity desserts on a menu card.

\section{Discussion}

The results obtained are in line with the hypothesis we formulated in introduction, supporting that the incidental exposure to the pear odour would impact food choices, and more precisely choices of desserts. In fact, the pear odour guided participants toward more 'fruity' desserts, but not toward more starters or main courses containing vegetables. The priming effect observed thus appears to be 'specific to the food cue'. In fact, pears are a fruit mainly consumed as a dessert and exposure to a pear odour had actually a significant impact on choices of desserts among participants subjected to the scented condition. This was consistent with the results obtained during our first study (Gaillet et al., 2013) and with the findings of previous research using a food odour as prime (Coelho et al., 2009; Fedoroff et al., 2003). We previously demonstrated that the incidental exposure to an odour of melon, which is a fruit mainly consumed as a starter in France, tended to influence choices of starters, but not choices of desserts, while the incidental exposure to an odour of pear, which is a fruit 
consumed as a dessert, had an impact on choices of desserts (Gaillet et al., 2013). These results suggested that the impact of a food odour on food choice seems specific to the course category corresponding to the context of consumption of the food represented by the prime. The results of the present experiment reinforce this conclusion.

At first sight, this high specificity and significant priming effect might suggest the presence of conscious processes underlying these effects. However, several elements let us assume that this priming experiment was actually based on implicit processes. According to Nisbett \& Wilson (1977), subjects may be "(a) unaware of the existence of a stimulus that importantly influenced a response, (b) unaware of the existence of the response, and (c) unaware that the stimulus has affected the response." (Nisbett \& Wilson, 1977, pp. 231). During our experiment, the participants were seated for 15 minutes in a room that was either odorised with a barely perceptible concentration of pear odour, or not scented for the control condition. Neither the participants, nor the experimenters who administered the Menu task and 'Investigation' Questionnaire in the test room, were informed about the presence of an odour in the waiting room. The participants were not informed of the real purpose of the experiment. Taking into account the results of the 'Investigation' Questionnaire, we assume that the priming effects observed in this experiment are based on implicit processes.

Concerning the mechanisms underlying these priming effects, it seems important to discuss how a non-attentively perceived odour might impact a food choice behaviour. Although, the existence of priming effects is now entirely established, explaining the underlying processes is a subject of controversy (Tenpenny, 1995), and opens a theoretical debate concerning the type of information implicated in memory. In fact, the issue is to understand whether priming effects might be mediated by abstract representations (e.g. pre-lexical and/or lexical units), episodic representations (e.g. traces), or both. In the first case, the spreading activation theory is one of the more classical and assumes that priming corresponds to the spread of activation by a prime via a network of interconnected concepts in long-term memory (Collins \& Loftus, 1975). Applied to our experiment, certain concepts related to a pear odour (e.g., 'pear'/'fruit') would become salient in the minds of primed individuals because of their non-conscious interpretation of the priming experience. These activations would then spread to trigger concepts linked more closely to the context of consumption, such as a 'fruity dessert'. This explanation is consistent with the findings of our previous experiments, based on which we proposed that a non-attentively perceived odour of melon or pear might activate not only a 'fruit and vegetable' concept, but also a concept corresponding to the context in which melon 
or pear is mainly consumed (i.e. as a starter or dessert) (Gaillet et al., 2013). In the second case, the compound cue theory offers an alternative where priming effects result from a combination of a prime and a stimulus (target) in short-term memory (Ratcliff \& McKoon, 1988). The compound cue formed by the prime and the target is then matched against information in long-term memory. Semantically or conceptually associated prime-target pairs will have a greater value of familiarity, and then be more easily retrieved from long-term memory than non-associated prime-target pairs. The closer the association between the prime and the target, the more the processing of the target will be facilitated. Applied to our experiment, the compound cue formed by the pear odour and the compote would result in a greater value of familiarity than the 'pear odour-brownie' compound. Consequently, the processing of the compote would be better facilitated than that of the brownie. Overall, the two explanations do not seem incompatible. The processes underlying priming effects may be based on the activation of neural networks. This activation drives a facilitated processing of a stimulus that is semantically, conceptually and/or perceptually linked to the prime, which then impacts a behaviour towards this stimulus.

The results obtained during our experiments, and discussion of their findings, might so far give an impression that the operation of priming is simple. But behind this apparent simplicity it must be admitted that the reality is quite complex, and that fortunately we are not so easily 'pushed around' by each stimulus we encounter. It is even more challenging to study priming effects on the expression of a particular (eating) behaviour. In fact, a priming paradigm needs to satisfy two major conditions in order to be effective. Firstly, priming effects occur if mental representations related to the prime, and links between these representations, pre-exist in the participants. Moreover, these links need to be sufficiently strong. The stronger the links, the more apparent should be the effects of priming. Secondly, if a priming effect corresponds to the production of a particular behaviour, participants need to be in a context where the expression of this particular behaviour is relevant (Aarts \& Dijksterhuis, 2003; Custers \& Aarts, 2005; Strahan, Spencer, \& Zanna, 2002). In addition, it must be noted that some limitations can be encountered, that should therefore be controlled as much as possible. In our experiment, a first limitation was that the participants presented probably inter-individual differences in olfactory sensitivity. In fact our procedure did not include a precise measure of each participant's detection threshold for the odour of pear. Nevertheless, we selected participants in a same age range, who did not report explicitly having some trouble in odour perception (anosmia). The participants were aged between 18 and 52, while the age-related 
decline in olfactory capacities rather concerns people from 60 years old (Doty et al., 1984; Murphy et al., 2002). A second limitation that we can rise concerns the fact that we actually can not fully assert whether the participants were not conscious about the presence of the olfactory prime. We pointed out that the olfactory prime we used was 'non-attentively' perceived rather than 'non-consciously' perceived. In fact, measuring awareness represents a problem in cognitive psychology that still does not seem to have been precisely and fully resolved (see Doyen, Klein, Simons \& Cleeremans, submitted, for a recent and comprehensive review). Further studies using specific measures of awareness or subliminal food odours should provide more sophisticated evidence to support the claim that "nonconsciously' perceived food odours can actually have an impact on eating behaviours. A last limitation might concerns the temporal aspect of the priming paradigm. In fact, we chose a pre-exposure procedure to the pear odour, instead of exposing participants during the Menu task, to avoid the pear odour mixes with the odours of the dishes that participants had to choose. This type of procedure seems to be favoured in experiments using olfactory priming in the food domain (Coelho et al., 2009; Fedoroff, Polivy \& Herman, 1997; Fedoroff et al., 2003). However, an exposure concomitant with food choices could appear more ecological. Many food choices situations indeed occur while people are perceiving food odours. The question to know whether different priming effects could be expected using an odour exposure concomitant with the food choices, instead of a pre-exposure, seems an interesting point that would deserve further investigations.

\section{Conclusions}

In conclusion, participants who were incidentally exposed to a pear odour were significantly more numerous in choosing to eat a dessert containing fruit than non-exposed participants. For the first time, this study provides scientific evidence that a non-consciously perceived fruity odour can influence actual food choices, guiding them toward more 'fruity' desserts. The involvement of implicit processes in food choices thus should be taken into account in guidelines and strategies designed to promote healthy eating.

\section{Acknowledgements}

The Burgundy Regional Council and FEDER funded this work. The authors would like to thank Françoise Durey (ChemoSens) and Valérie Feyen for their precious logistical assistance in the conduct of the experiments; The Scentys Fragrance Company for its work on odorant 
encapsulation, and Vicky Hawken for linguistic assistance. The authors have no conflict of interest to disclose.

\section{References}

Aarts, H., \& Dijksterhuis, A. (2003). The silence of the library: environment, situational norm, and social behavior. Journal of Personality and Social Psychology, 84, 18-28.

Bargh, J. A., \& Chartrand, T. L. (1999). The unbearable automaticity of being. American Psychologist, 54, 462-479.

Bargh, J. A., \& Ferguson, M. J. (2000). Beyond behaviorism: on the automaticity of higher mental processes. Psychological Bulletin, 126, 925-945.

Bensafi, M., Rouby, C., Farget, V., Bertrand, B., Vigouroux, M., \& Holley, A. (2002a). Autonomic nervous system responses to odours: the role of pleasantness and arousal. Chemical Senses, 27, 703-709.

Bensafi, M., Rouby, C., Farget, V., Bertrand, B., Vigouroux, M., \& Holley, A. (2002b). Psychophysiological correlates of affects in human olfaction. Neurophysiologie Clinique-Clinical Neurophysiology, 32, 326-332.

Boesveldt, S., Frasnelli, J., Gordon, A. R., \& Lundstrom, J. N. (2010). The fish is bad: negative food odors elicit faster and more accurate reactions than other odors. Biological Psychology, 84, 313-317.

Coelho, J. S., Polivy, J., Herman, C. P., \& Pliner, P. (2009). Wake up and smell the cookies. Effects of olfactory food-cue exposure in restrained and unrestrained eaters. Appetite, $52,517-520$.

Collins, A. M., \& Loftus, E. F. (1975). Spreading activation theory of semantic processing. Psychological Review, 82, 407-428.

Custers, R., \& Aarts, H. (2005). Positive affect as implicit motivator: on the nonconscious operation of behavioral goals. Journal of Personality and Social Psychology, 89, 129142.

De Martino, B., Kumaran, D., Seymour, B., \& Dolan, R. J. (2006). Frames, biases, and rational decision-making in the human brain. Science, 313, 684-687.

Dijksterhuis, A., Bos, M. W., Nordgren, L. F., \& van Baaren, R. B. (2006). On making the right choice: the deliberation-without-attention effect. Science, 311, 1005-1007.

Doty, R. L., Shaman, P., Appelbaum, S. L., Giberson, R., Siksorski, L., \& Rosenberg, L. (1984). Smell identification: Changes with age. Science, 226, 1441-1443.

Doyen, S., Klein, O., Simons, D., \& Cleeremans, A. (submitted for publication). On the other side of the mirror. Priming in cognitive and social psychology. Social

Cognition. Fedoroff, I. C., Polivy, J., \& Herman, C. P. (1997). The effect of pre-exposure to food cues on the eating behavior of restrained and unrestrained eaters. Appetite, 28, $33-47$.

Fedoroff, I. C., Polivy, J., \& Herman, C. P. (2003). The specificity of restrained versus unrestrained eaters' responses to food cues: general desire to eat, or craving for the cued food? Appetite, 41, 7-13. 
Finlayson, G., King, N., \& Blundell, J. (2008). The role of implicit wanting in relation to explicit liking and wanting for food: implications for appetite control. Appetite, 50, 120-127.

Friese, M., Hofmann, W., \& Wanke, M. (2008). When impulses take over: moderated predictive validity of explicit and implicit attitude measures in predicting food choice and consumption behaviour. British Journal of Social Psychology, 47, 397-419.

Friese, M., Waenke, M., \& Plessner, H. (2006). Implicit consumer preferences and their influence on product choice. Psychology \& Marketing, 23, 727-740.

Fusari, A., \& Ballesteros, S. (2008). Identification of odors of edible and nonedible stimuli as affected by age and gender. Behavior Research Methods, 40, 752-759.

Gaillet, M., Sulmont-Rossé, C., Issanchou, S., Chabanet, C., \& Chambaron, S. (2013). Priming effects of an olfactory food cue on subsequent food-related behaviour. Food Quality and Preference, 30, 274-281.

Greenwald, A. G., \& Banaji, M. R. (1995). Implicit social cognition: attitudes, self-esteem, and stereotypes. Psychological Review, 102, 4-27.

Hoover, K. C. (2010). Smell with inspiration: the evolutionary significance of olfaction. American Journal of Physical Anthropology, 53, 63-74.

Jacquier, C., Bonthoux, F., Baciu, M., \& Ruffieux, B. (2012). Improving the effectiveness of nutritional information policies: assessment of unconscious pleasure mechanisms involved in food-choice decisions. Nutrition Reviews, 70, 118-131.

Jansen, A., \& van den Hout, M. (1991). On being led into temptation: "counterregulation" of dieters after smelling a "preload". Addictive Behaviors, 16, 247-253.

Kahneman, D., \& Tversky, A. (2000). Choices, values and frames. In. New York: Cambridge University Press.

Klajner, F., Herman, C. P., Polivy, J., \& Chhabra, R. (1981). Human obesity, dieting, and anticipatory salivation to food. Physiology \& Behavior, 27, 195-198.

Köster, E. P. (2009). Diversity in the determinants of food choice: a psychological perspective. Food Quality and Preference, 20, 70-82.

Legoff, D. B., \& Spigelman, M. N. (1987). Salivary response to olfactory food stimuli as a function of dietary restraint and body-weight. Appetite, 8, 29-35.

Murphy, C., Schubert, C. R., Cruickshanks, K. J., Klein, B. E. K., Klein, R., \& Nondahl, D. M. (2002). Prevalence of olfactory impairment in older adults. Jama-Journal of the American Medical Association, 288, 2307-2312.

Nisbett, R. E., \& Wilson, T. D. (1977). Telling more than we can know: verbal reports on mental processes. Psychological Review, 84, 231-259.

Ratcliff, R., \& McKoon, G. (1988). A retrieval theory of priming in memory. Psychological Review, 95, 385-408.

Rogers, P. J., \& Hill, A. J. (1989). Breakdown of dietary restraint following mere exposure to food stimuli: interrelationships between restraint, hunger, salivation, and food intake. Addictive Behaviors, 14, 387-397.

Royet, J. P., Zald, D., Versace, M., Costes, N., Lavenne, F., Koenig, O., et al. (2000). Emotional responses to pleasant and unpleasant olfactory, visual, and auditory stimuli: a positron emission tomography study. Journal of Neuroscience, 20, 7752-7759. 
Strahan, E. J., Spencer, S. J., \& Zanna, M. P. (2002). Subliminal priming and persuasion: striking while the iron is hot. Journal of Experimental Social Psychology, 38, 556-568.

Tenpenny, P. L. (1995). Abstractionist versus episodic theories of repetition priming and word identification. Psychonomic Bulletin \& Review, 2, 339-363.

Wansink, B., \& Sobal, J. (2007). Mindless eating: the 200 daily food decisions we overlook. Environment and Behavior, 39, 106-123.

Zald, D. H., Lee, J. T., Fluegel, K. W., \& Pardo, J. V. (1998). Aversive gustatory stimulation activates limbic circuits in humans. Brain, 121, 1143-1154.

Zald, D. H., \& Pardo, J. V. (1997). Emotion, olfaction, and the human amygdala: amygdala activation during aversive olfactory stimulation. Proceedings of the National Academy of Sciences of the United States of America, 94, 4119-4124. 


\section{Table 1}

Means of ratings on declared hedonicity for each dish served buffet-style. For each course of a typical French meal (starter, main course and dessert), two choices were offered: a dish containing fruits or vegetables or a dish without fruit or vegetable. The weight and the calories content are given in this table for the reader, but the participants did not have this information. No dish contained the fruit pear.

\begin{tabular}{|c|c|c|c|c|}
\hline & & $\begin{array}{c}\text { Weight } \\
(\mathrm{g})\end{array}$ & $\begin{array}{c}\text { Calories } \\
\text { content } \\
(\mathrm{kCal})\end{array}$ & $\begin{array}{l}\text { Declared } \\
\text { hedonicity }\end{array}$ \\
\hline \multirow{3}{*}{$\begin{array}{l}\text { 'Without fruit } \\
\text { or vegetable' } \\
\text { 'Fruit and } \\
\text { vegetables' }\end{array}$} & Starters & & & \\
\hline & Assiette de charcuterie (plate of cold meat) & 120 & 379 & $\begin{array}{l}M=6.59 ; \\
S E=0.61\end{array}$ \\
\hline & Carottes râpées (grated carotts) & 150 & 108 & $\begin{array}{l}M=6.61 ; \\
S E=0.45\end{array}$ \\
\hline \multirow{4}{*}{$\begin{array}{l}\text { 'Without fruit } \\
\text { or vegetable' } \\
\text { 'Fruit and } \\
\text { vegetables' }\end{array}$} & Main courses & & & \\
\hline & Cannelloni bolognaise (cannelloni Bolognese) & 350 & 385 & $\begin{array}{l}M=6.83 ; \\
S E=0.55\end{array}$ \\
\hline & Saumon et risotto verde (Salmon and risotto verde) & 350 & 382 & $\begin{array}{l}M=6.91 ; \\
S E=0.48\end{array}$ \\
\hline & Desserts & & & \\
\hline $\begin{array}{l}\text { 'Without fruit } \\
\text { or vegetable' }\end{array}$ & Brownie (brownie) & 71 & 328 & $\begin{array}{l}M=7.69 ; \\
S E=0.43\end{array}$ \\
\hline $\begin{array}{l}\text { 'Fruit and } \\
\text { vegetables' }\end{array}$ & Compote de pomme (apple compote) & 100 & 78 & $\begin{array}{l}M=7.60 \\
S E=0.45\end{array}$ \\
\hline
\end{tabular}




\section{Figure 1}

Proportion of choices of dishes with fruit or vegetables for each course (starter, main course and dessert) in the control condition (white bars) and the scented condition (grey bars); $90 \%$ Confidence Intervals; $* * * p<.001$

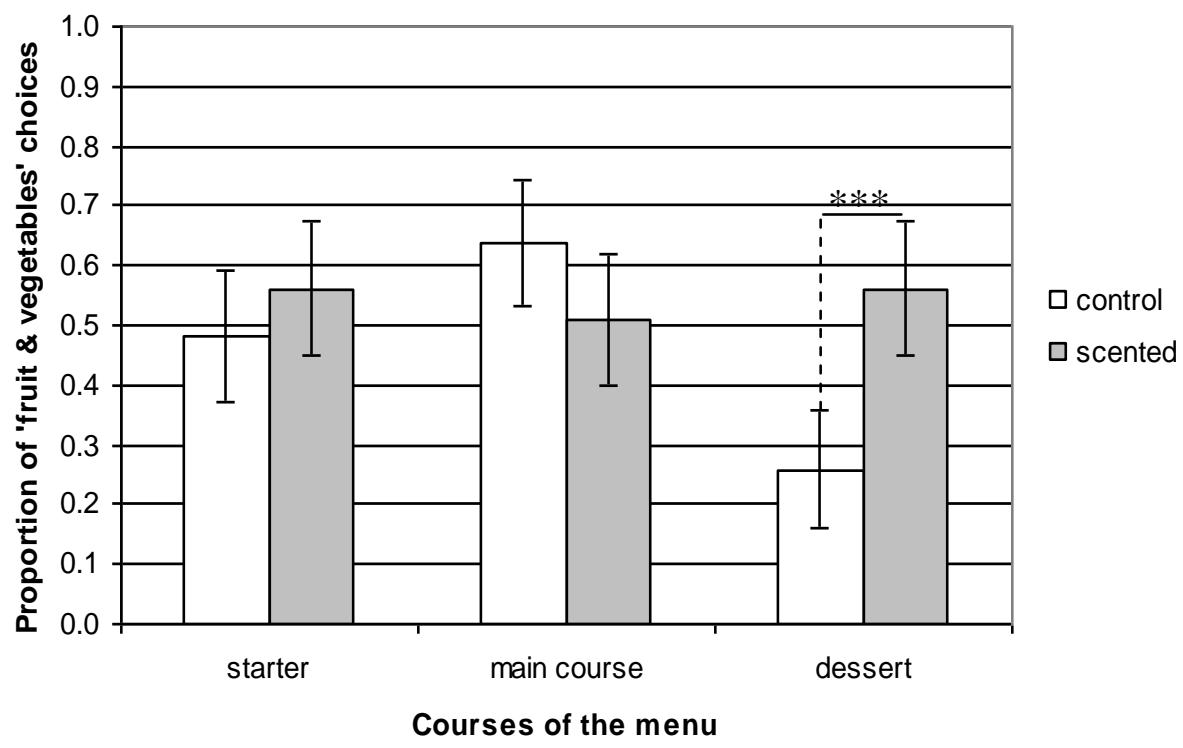

